\title{
Seria a semiologia de Saussure fundamento e justificativa para o método de pesquisa de revisão de literatura em Psicanálise?
}

\author{
Would Saussurian semiology be the basis and justification for \\ literature review of the psychoanalytical research method?
}

\author{
Victor Eduardo Silva BENTO²
}

\begin{abstract}
Resumo
Esta revisão de literatura analisou criticamente a noção de Semiologia em Saussure, 1916, no campo da Lingüística, caracterizando seus principais componentes e aspectos constitutivos, e destacando as operações necessárias numa pesquisa semiológica. Foram abordados os seguintes pontos: 1) Saussure, a Semiologia como Psicologia Social, o corte do signo e a Lingüística Estrutural; 2) A diferença entre Semiologia e Lingüística em Saussure; 3) Lévi-Strauss, a Antropologia estrutural e os mitos como língua, fala e sistema universal de signos; 4) A semântica em Saussure; e 5) A etimologia em Saussure. Finalmente, na conclusão, interrogou-se se o método semiológico de Saussure poderia ou não ser justificativa e fundamento para o método de pesquisa de revisão de literatura em psicanálise.
\end{abstract}

Palavras-chave: método de pesquisa em psicanálise; revisão de literatura; semiologia saussuriana.

\begin{abstract}
This literature review analyzed Saussurian semiology, 1916, in the linguistics area, showing its principal components, constitutive aspects and the operations of semiology/search. The following points were discussed: 1) Saussure, semiology as a social psychology, sign cut and structural linguistics; 2) The difference between semiology and linguistics in Saussurian approach; 3) Lévi-Strauss, structural anthropology and the myths as a "language", "parole", and universal system of signs; 4) Saussurian semantics; and 5) Saussurian etymology. As a conclusion, this question was asked: Could the semiological method by Saussure be the basis and justification for literature review as a search method in psychoanalysis?
\end{abstract}

Key words: psychoanalysis search method; literature review; saussurian semiology.

Trata-se aqui de pesquisa de revisão de literatura em torno do seguinte problema principal: seria a Semiologia de Saussure fundamento e justificativa para o método de pesquisa de revisão de literatura em psicanálise?
Se está em questão a noção de "método de pesquisa de revisão de literatura em psicanálise", faz-se mister definir alguns termos para melhor precisar o problema central deste artigo, justificar seu título e delimitar os limites do alcance de sua abrangência.

\section{VVV}

1 Artigo elaborado a partir da tese de V.E.S. BENTO, intitulada: "La passion amoureuse 'toxique': une approche psychanalytique a partir de la sémiologie et du narcissisme chez Freud". Université Paris 7, 1996.

2 Professor Doutor, Departamento de Psicometria, Instituto de Psicologia, Universidade Federal do Rio de Janeiro. Av. Pasteur, 250, Pavilhão Nilton Campos, Praia Vermelha, 22290-240, Rio de Janeiro, RJ, Brasil. E-mail:<victorbento@oi.com.br>. 
Assim, para começar, caberia destacar a definição de "método": "1. Caminho pelo qual se chega a um determinado resultado, ainda que esse caminho não tenha sido fixado de antemão de modo deliberado e refletido. 2. Programa que regula previamente uma série de operações que se devem realizar, apontando erros evitáveis, em vista de um resultado determinado" (Ferreira, 1975, p. 919).

No "Vocabulário Técnico e Crítico da Filosofia", Lalande proporá uma definição de "método" no seu sentido "A" muito semelhante a essa de Ferreira acima, porém com maior detalhamento, como segue:

A. Etimologicamente, 'demanda' ...; e, por conseqüência, esforço para atingir um fim, investigação, estudo ...; de onde nos modernos, duas acepções muito próximas, ainda que possíveis de distinguir.

10. Caminho pelo qual se chegou a determinado resultado, mesmo quando esse caminho não foi previamente fixado de uma maneira premeditada e refletida. 'Chama-se aqui ordenar à ação do espírito pela qual, tendo sobre um mesmo assunto... diversas idéias, diversos juízos, diversos raciocínios, ele os dispõe de maneira mais adequada para conhecer esse assunto. É o que também se chama método. Tudo isso se faz naturalmente e algumas vezes melhor por aqueles que não aprenderam qualquer lógica do que por aqueles que as aprenderam.'Lógica de Port-Royal, introdução, 6-7.

Esta palavra diz-se muitas vezes, neste sentido, dos processos habituais de um espírito ou de um grupo de espíritos, processos que se podem observar e definir por indução, quer para em seguida os praticar mais seguramente, quer para os criticar e mostrar a sua invalidade.

$2^{\circ}$. Programa que regula antecipadamente uma seqüência de operações a executar e que assinala certos erros a evitar, com vista a atingir um resultado determinado (Lalande, 1996, p.678).

A noção de método aplicada à Psicanálise demanda também algumas precisões. Pois se pode i⿱宀 pensar em pelo menos três sentidos para a expressão 荋 "método psicanalítico". Laplanche e Pontalis (1998, p.384)

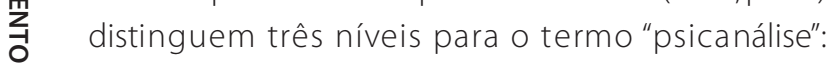
"A) Um método de investigação que consiste essencialmente em evidenciar o significado inconsciente das

408 palavras, das ações, das produções imaginárias (sonhos, fantasias, delírios) de um sujeito" - correspondendo ao que se pode entender como sendo o sentido de método de pesquisa clínica em psicanálise, em geral chamado "estudo de caso"."B) Um método psicoterápico baseado nesta investigação e especificado pela interpretação controlada da resistência, da transferência e do desejo" - correspondendo ao que se pode entender como sendo o sentido de método clínico em psicanálise. "C) Um conjunto de teorias psicológicas e psicopatológicas em que são sistematizados os dados introduzidos pelo método psicanalítico de investigação e de tratamento" - correspondendo ao que se pode entender como sendo o sentido de método de pesquisa teórica em psicanálise, em geral chamado "revisão de literatura".

Vê-se, então, acima em destaque o termo "psicanálise" relacionado a dois sentidos de método de pesquisa: o método de pesquisa clínica e o método de pesquisa teórica. Eainda se vê em evidência "psicanálise" como método clínico. Cabe aqui sublinhar que"método clínico"é diferente de "método de pesquisa clínica". Não é objetivo deste artigo se aprofundar na discussão das diferenças entre estes dois últimos métodos da psicanálise, mas sim apenas mencioná-los para que possam ser percebidos pelo leitor como coisas distintas e diferentes daquilo a que se quer chegar neste artigo.

Este trabalho pretende pensar precisamente se a Semiologia de Saussure poderia ser fundamento e justificativa do terceiro sentido de "psicanálise" definido por Laplanche e Pontalis como remetendo ao sentido de método de pesquisa de revisão de literatura em psicanálise. Esse método de pesquisa consiste no procedimento de investigar textos, escritos, etc., passíveis de receberem a ótica da psicanálise. Portanto, este artigo pretende chegar a uma contribuição no campo da epistemologia do método de pesquisa de revisão de literatura em psicanálise.

Mas de onde veio essa preocupação com o estudo do método de pesquisa de revisão de literatura em Psicanálise? Como justificar a importância da presente pesquisa? Porque estudar a temática da "pesquisa em Psicanálise"? E por que valorizar o estudo da "Revisão de Literatura" como método de pesquisa em Psicanálise? Para responder a tais questões, apresentam-se a seguir os seguintes motivos:

10) Sobretudo tratando-se do ensino da psicanálise nas universidades, a questão da "pesquisa em 
Psicanálise" se revela como especialmente relevante já que a "pesquisa" é a alma de toda e qualquer universidade.

20) Observações específicas do autor deste trabalho, em sua experiência como orientador de monografias e de estágios de pesquisa na área Psicanálise das Toxicomanias, principalmente de alunos do curso de graduação em Psicologia da Universidade Federal dp Paraná (UFPR), Centro de Estudos das Toxicomanias (CET) Dr. Claude Olievenstein da UFPR, desde o ano de 2000, parecem ter indicado a importância do estudo do método de revisão de literatura em psicanálise. Para justificar essa afirmação, seguem algumas informações sobre tais estágios de pesquisa no CET, bem como o relato das observações que motivaram a presente pesquisa, que será então partilhado com o leitor, que talvez possa encontrar eco na sua experiência pessoal e profissional.

- No período de outubro de 1999 a maio de 2005, a formação em pesquisa no campo da Psicanálise das Toxicomanias ofertada pelo CET possuía três anos de duração. No primeiro ano os alunos realizavam apenas tarefas de revisão de literatura. No segundo ano o aluno dava continuidade à revisão de literatura do primeiro ano, e era introduzido na prática clínica, passando a fazer também estudo de caso. O terceiro ano previa a continuidade da prática desses três métodos psicanalíticos: dois de pesquisa (revisão de literatura e estudo de caso) e um método clínico (psicoterapia).

- No aprendizado da Psicanálise, os alunos tomavam contato com a natureza principalmente clínica dessa disciplina. Ao lado disso, particularmente no ano de 2003, por ocasião das defesas das monografias desenvolvidas no CET, críticas dos membros das bancas dessas monografias, constituídas por psicanalistas (alguns até didatas) e/ou professores-pesquisadores universitários também do campo da psicanálise, vieram a influenciar a valorização do método de pesquisa de estudo de caso em relação ao de revisão de literatura. 0 imaginário do grupo de pesquisadores deste centro constituído por professores e alunos parecia algumas vezes tomado por um cenário de aparente inversão de valores, no qual se percebiam, ainda que implicitamente, as seguintes questões: seria o estudo de caso o método, por excelência, para a pesquisa psicanalítica, já que seria a priori nele onde se poderia estudar a clínica tão valorizada pela Psicanálise? Se a clínica é essencial na psicanálise, porque iniciar o ensino da psicanálise, particularmente da pesquisa em psicanálise, pela prática da revisão de literatura, no lugar do estudo de caso? Qual a validade em ciência e na psicanálise do método de pesquisa de revisão de literatura? A discussão e o aprofundamento de tais questões só poderiam ocorrer se fosse estudada a questão da revisão de literatura como método de pesquisa em psicanálise.

- Cabe destacar uma das críticas dos membros dessas bancas de monografias acima referidas. Observou-se que o estudo teórico realizado no primeiro ano do CET para a revisão de literatura algumas vezes criava pré-conceitos, levando alguns alunos a tentar encaixar a teoria no estudo de caso realizado no segundo ano do CET. Esse fato serviu para aumentar a resistência do grupo para aceitar o método de revisão de literatura em pesquisa psicanalítica. Isso pareceu justificar os esforços no sentido de estudar no CET o método de revisão de literatura para discutir seus fundamentos, justificar sua importância, esclarecer seus eventuais riscos e eliminar pré-conceitos a seu respeito.

30) Na literatura são encontrados muitos estudos sobre o estudo de caso em psicanálise, enquanto são escassas as referências bibliográficas sobre o método de revisão de literatura em pesquisa psicanalítica. Conclui-se então que é importante que se aumentem as pesquisas sobre o método de pesquisa de revisão de literatura em psicanálise.

Mas por que recorrer especificamente à Semiologia de Saussure (1916/1995a) como fundamento e justificativa de uma prática de pesquisa de revisão de literatura em psicanálise? Primeiramente deve-se esclarecer que Saussure não propõe essa disciplina para servir a psicanálise, mas a Psicologia social. Contudo esse autor tem sido utilizado como fundamento para as produções literárias de renomados autores da psicanálise, dentre os quais se podem destacar em particular aquelas de Lacan (ver Bento, 1996; Lacan, 1996, 1998). Além disso, como se verá a seguir, a Semiologia proposta por Saussure (1916/1995a) parece funcionar também como um método de revisão de literatura, podendo servir como justificativa e fundamento para a pesquisa bibliográfica em psicanálise. Eis aqui a hipótese central deste trabalho. 
Para aprofundar essa hipótese não se pretende aqui realizar uma exaustiva revisão de literatura sobre o tema do método de pesquisa de revisão de literatura em psicanálise. Pretende-se, sim, estudar a Semiologia no pensamento de Saussure para, apenas no momento da conclusão desta pesquisa, discutir se essa Semiologia saussuriana poderia ser pensada como fundamento e justificativa do método de pesquisa de revisão de literatura em psicanálise.

Como justificar esses limites da delimitação do alcance dessa pesquisa? Por um lado, como se disse acima, são escassas as pesquisas tratando diretamente desse tema do método de pesquisa de revisão de literatura em psicanálise. Pensou-se, então, que diante dessa escassez de trabalhos sobre a mesma temática, se deveria pesquisá-la indiretamente, isto é, por meio do estudo do método semiológico em Saussure. Por outro lado, a própria Semiologia encontra-se em estado embrionário na obra de Saussure (1916/1995a). Esse autor, pai dessa Semiologia da Lingüística estrutural, ao criá-la, apresenta-a em apenas quatro páginas no contexto do seu livro sobre Lingüística geral de 520 páginas, sendo, obviamente, inúmeras as lacunas nesse momento embrionário. O objetivo aqui será buscar uma compreensão dessas lacunas não nos autores da Semiologia pós-Saussure, mas em Saussure mesmo, mais precisamente em sua Lingüística estrutural apresentada nesse livro de 520 páginas. Portanto, para aprofundar os elementos dessa proposta semiológica original de Saussure, será necessário recorrer à Lingüística deste autor, o que já não será tarefa fácil. Além dessa dificuldade, acresce-se o fato de o pensamento saussureano sobre sua proposta semiológica apresentar aparentes contradições. Por final, considerando também o limite espacial de escrita num artigo científico, optou-se por restringir o alcance desta pesquisa ao estudo deste esboço de Semiologia apenas na obra de Saussure, procurando discutir as possíveis soluções para as aparentes contradições do pensamento deste autor sobre a temática em questão. Assim delimitado o alcance . desta pesquisa (o estudo da Semiologia de Saussure a [ partir de Saussure mesmo), pretende-se, então, apenas on no momento da conclusão deste artigo, discutir se essa Semiologia de Saussure poderia ser pensada como fundamento e justificativa do método de pesquisa de revisão de literatura em Psicanálise.
Apresentadas as justificativas iniciais e a delimitação dos limites do alcance desta pesquisa pode-se agora apresentar o plano de escrita deste artigo. A seqüência dos tópicos que serão discutidos ao longo deste texto é:"Saussure e sua proposição de Semiologia como Psicologia Social, de corte do signo e de Lingüística Estrutural"; "A diferença entre Semiologia e Lingüística em Saussure: uma questão de distinção entre linguagem, língua e fala?";"'Lévi-Strauss: sua Antropologia Estrutural e sua abordagem dos mitos como linguagem do domínio da língua, da fala e de um sistema universal de signos"; "A Semântica em Saussure"; e "A Etimologia em Saussure". Finalmente, na "Conclusão", pretende-se discutir o problema central desta pesquisa, isto é, se o método semiológico de Saussure construído, desenvolvido e discutido nos itens anteriores poderia ou não ser justificativa e fundamento para o método de pesquisa de Revisão de Literatura em Psicanálise.

Esta será, então, uma pesquisa de revisão de literatura para justificá-la como método de pesquisa em psicanálise, a partir da Semiologia saussuriana, disciplina que será desenvolvida ao longo desta pesquisa a partir principalmente dos legados de Saussure mesmo, seu pai-criador.

\section{Saussure e sua proposição de Semiologia como Psicologia Social, de corte do signo e de Lingüística estrutural}

Saussure dá à Semiologia a seguinte definição geral:

Pode-se, então, conceber uma ciência que estude a vida dos signos no seio da vida social; ela constituiria uma parte da Psicologia social e, por conseguinte, da Psicologia geral; chamá-la-emos de Semiologia (do grego semeîn, 'signo'). Ela nos ensinará em que consistem os signos, que leis os regem. Como tal ciência não existe ainda, não se pode dizer o que será; ela tem direito, porém, à existência; seu lugar está determinado de antemão. A Lingüística não é senão uma parte dessa ciência geral; as leis que a Semiologia descobrir serão aplicáveis à Lingüística e esta se achará dessarte vinculada a um domínio bem definido no conjunto dos fatos humanos. Cabe ao psicólogo determinar o lugar exato da Semiologia. (Saussure, 1916/1995b, p.24) - ver passagem correspondente na edição francesa: Saussure (1916/1995a, p.33). 
Como se pode ver, a Semiologia foi inicialmente caracterizada pelo fato de ela constituir uma "ciência ... dos signos". Para definir o signo, que é a unidade lingüística e o objeto de estudo principal dessa ciência, Saussure começa por evocar sua composição:

O signo lingüístico une não uma coisa e uma palavra, mas um conceito e uma imagem acústica. Esta não é o som material, coisa puramente física, mas a impressão (empreinte) psíquica desse som, a representação que dele nos dá o testemunho de nossos sentidos (Saussure, 1916/1995b, p.80) - ver passagem correspondente na edição francesa: Saussure (1916/1995a, p.98).

Depois de ter assim colocado a ênfase na idéia do signo lingüístico como "entidade psíquica de duas faces", Saussure acabará por considerar sua definição ambígüa ("no uso corrente este termo - signo - designa geralmente apenas a imagem acústica") e por propor uma outra definição mais conveniente:"Propomo-nos a conservar o termo signo para designar o total, e a substituir conceito e imagem acústica respectivamente por significado e significante." (Saussure, 1916/1995b, p.81) - ver passagem correspondente na edição francesa: Saussure (1916/1995a, p.99).

Com o corte da unidade lingüística - o signo - em dois elementos - o significado e o significante, Saussure vai, por um lado, fundar a natureza do signo e, por outro lado, marcar por sua originalidade uma ruptura com o pensamento tradicional. Como assinalam Ducrot e Todorov (1988, p.131):"Era a propósito da atribuição dos nomes às coisas que (na Antigüidade grega) os sofistas colocavam o problema."- Ver passagem correspondente na edição francesa: - Ducrot e Schaeffer (1995, p.270). Com Saussure (1916/1995b, p.80): "o signo lingüístico une não uma coisa e uma palavra, mas um conceito e uma imagem acústica". Além disso, trata-se para este autor de valorizar uma dimensão psíquica, pois, segundo ele, a imagem acústica não é "o som material, coisa puramente física, mas a impressão (empreinte) psíquica desse som, a representação que dele nos dá o testemunho de nossos sentidos" (Saussure, 1916/1995b, p.80). É o que fará da Semiologia, esta ciência dos signos, uma Psicologia. A Semiologia, escreve Saussure (1916/1995b, p.24):"constituiria uma parte da Psicologia Social e, por conseguinte, da Psicologia geral".

Por outro lado, Saussure vai marcar uma nova etapa na Lingüística moderna e, especificamente, o nascimento da Lingüística Estrutural. Como lembram Ducrot eTodorov (1988, p.134):"Esta tese da originalidade do CORTE LINGÜÍSTICO é apresentada no Cap. IV da 2a Parte do Cours de linguistique générale de SAUSSURE; foi retomada pela maioria dos fonólogos, e, em geral, por toda a escola estruturalista." - Ver passagem correspondente na edição francesa: Ducrot e Schaeffer (1995, p.277). Para melhor precisar essa Lingüística Estrutural, será citada a seguir uma outra passagem desse mesmo dicionário: "A essa organização inerente a toda língua, Saussure denomina SISTEMA (seus sucessores falam amiúde de ESTRUTURA). ... sistema ou estrutura da língua: os elementos lingüísticos não têm nenhuma realidade independentemente de sua relação com o todo" (Ducrot \& Todorov, 1988, p.27) - ver passagem correspondente na edição francesa: Ducrot e Schaeffer (1995, p.31).

A língua, se verá mais adiante, é o objeto da Lingüística e um sistema de signos. Ela aparece aqui como um sistema porque ela é constituída por um conjunto de elementos, de signos, que "não têm nenhum caráter próprio independentemente de suas relações mútuas no interior do todo" (Ducrot \& Schaeffer, 1995, p.31).

O signo, como objeto particular da Semiologia, não é abordado aqui pelo dicionário. Parece que tal falta se explica pelo fato de que na época do Curso de Lingüística Geral de Saussure essa ciência dos signos estava ainda em gestação, inacabada. Saussure parecia ter consciência disso, pois ele escreve:"Como tal ciência não existe ainda, não se pode dizer o que será; ela tem direito, porém, à existência" (Saussure, 1916/1995b, p.24). Com efeito, ele só Ihe consagrou um único subitem de quatro páginas (Saussure, 1916/1995a, p.32-35) no conjunto de seu Curso de Lingüística Geral de 520 páginas na edição francesa.

Seguindo o mesmo princípio que o autor utiliza para pensar a língua, objeto da Lingüística, não se poderia então dizer que o signo, objeto da Semiologia, sendo constituído igualmente por um conjunto de elementos, o significante e o significado, possuindo relações mútuas no interior de sua unidade lingüística, não seria ele também um sistema? Mais precisamente, por analogia com esse raciocínio que vê a língua como sistema, não se poderia dizer que o signo é um sistema em si, mas dependente das relações mútuas com outros sistemas- 
signos no interior do sistema lingüístico? Não se trataria em Saussure da proposição de uma Semiologia igualmente estrutural?

Encontra-se também em Dor (1985, 1992), desta vez no domínio da Psicanálise, uma caracterização da Lingüística Estrutural de Saussure que traz esclarecimentos parecidos àqueles colocados em evidência por Ducrot e Schaeffer (1995) - a propósito da associação entre o ponto de vista dos sistemas e o ponto de vista estrutural -, mas que valoriza um outro aspecto ao acrescentar a oposição saussuriana entre sincronia e diacronia. Dor começa por evocar a noção de estrutura em geral.

A atitude estruturalista é uma estratégia de promoção de uma nova inteligibilidade que rompe com certas formas de pensar os objetos. ... porquanto pôde colocar em evidência, com relação a elementos e objetos, sistemas de relações que não aparecem imediatamente entre eles. ... Em particular, trata-se de renunciar a um certo tipo de descrição da natureza dos objetos, de suas qualidades, de suas propriedades específicas. Em contrapartida, o importante consiste em dar-se a possibilidade de fazer advir relações, aparentemente dissimuladas, que existem entre eles ou entre seus elementos (Dor, 1992, p.22) - ver passagem correspondente na edição francesa: Dor (1985, p.28).

No que concerne mais particularmente o nascimento da Lingüística Estrutural após Saussure, assim como a dupla caracterização de uma abordagem saussuriana como sendo ao mesmo tempo sincrônica e diacrônica, Dor escreve:

O ponto de vista estruturalista em lingüística surgiu com a introdução da dimensão sincrônica no estudo da língua. Esta introdução do registro sincrônico, que devemos a F. Saussure, estipula que um tal estudo não pode ser reduzido a uma perspectiva puramente diacrônica, quer dizer, histórica. De fato, a história de uma palavra não permite dar conta de sua significação presente, pois esta significação depende do sistema da língua. Este sistema reside num certo número de leis de equilíbrio que estão na dependência direta da sincronia (Dor, 1992, p.26) - ver passagem correspondente na edição francesa: Dor (1985, p.32).

Compreende-se aqui que se trata em Saussure

412 de uma Lingüística que valoriza uma sincronia diacrô- nica, se assim se pode dizer, posto que o sistema de signos (sincronia das palavras), que permite se "dar conta de sua significação presente", das relações entre seus próprios elementos (os signos), é valorizado ao mesmo tempo que sua análise histórica, pois um "estudo não pode ser reduzido a uma perspectiva puramente diacrônica". Se se retoma a analogia (raciocínio por analogia) entre a Lingüística e a Semiologia, não se poderia esperar encontrar em Saussure uma Semiologia, ela também, ao mesmo tempo, sincrônica e diacrônica?

Não é encontrada a esse propósito nenhuma indicação diretamente enunciada no único e pequeno subitem que Saussure (1916/1995a, p.32-35) consagra à Semiologia nessa obra que trata essencialmente da Lingüística. Não seria necessário então procurar neste autor indicações indiretas que evocassem esta Semiologia ao mesmo tempo sincrônica e diacrônica? Se se considera que a Semiologia, no Curso de Lingüística Geral de Saussure, se encontrava ainda em gestação, não seria então natural se resignar em apenas poder supor essa Semiologia a partir das analogias entre ela e a Lingüística a partir das pistas indiretas que Saussure teria deixado?

A Semiologia terá ainda uma outra delimitação, posto que ela será o estudo dos signos, mas "no seio da vida social" (Saussure, 1916/1995b, p.24). Para precisar a compreensão daquilo que ele chama de "social", de"vida social", Saussure (1916/1995b, p. 24) evocará"um domínio bem definido no conjunto dos fatos humanos", ilustrando-os pelos"ritos, costumes, etc." (Saussure, 1916/ 1995b, p.25). Parece que é de fato a valorização de uma tal dimensão social que conduzirá o autor a especificar a qual Psicologia se ligará a Semiologia: essa última "constituiria uma parte da Psicologia Social e, por conseguinte, da Psicologia Geral" (Saussure, 1916/1995b, p.24); "a Lingüística não (seria) senão uma parte dessa ciência geral" (Saussure, 1916/1995b, p.24).

Antes de terminar este item, será ainda feita uma última observação. Como demonstra seu título, vê-se uma oscilação entre a Semiologia, a Lingüística e o signo que Ihes é comum. Mais precisamente, como foi visto que a Semiologia é a ciência dos signos e a Lingüística a ciência da língua, essa entendida como um sistema de signos, como compreender então a diferença entre essas duas ciências? Como compreender que Saussure (1916/1995b, p.24) diferencie duas ciências relativas ao 
signo, dizendo que"a Lingüística não é senão uma parte dessa ciência geral" que é a Semiologia? Em que, mais precisamente, a Semiologia seria afinal mais geral que a Lingüística no que concerne a questão dos signos? Tais questões serão tratadas no item seguinte.

\section{A diferença entre Semiologia e Lingüística em Saussure: uma questão de distinção entre linguagem, língua e fala?}

A Semiologia pareceria ser concebida também como uma ciência que estuda a língua, se confundindo assim com a Lingüística. É ao menos o que se compreende à primeira vista quando se lê em particular as três passagens do autor que serão citadas a seguir. Primeiramente, Saussure inicia a introdução de seu primeiro capítulo com a definição de Lingüística em torno do seu verdadeiro e único objeto: a língua, os fatos de língua. Ele escreve:"a ciência que se constituiu em torno dos fatos da língua passou por três fases sucessivas antes de reconhecer qual é o seu verdadeiro e único objeto" (Saussure, 1916/1995b, p.7) - ver passagem correspondente na edição francesa: Saussure (1916/1995a, p.13).

Mais adiante, no subitem consagrado à Semiologia, se, por um lado, Saussure a diferencia da Lingüística quando situa a primeira como "ciência geral", da qual "a Lingüística não é senão uma parte" (Saussure, 1916/1995b, p.24), por outro lado ele a aproxima à língua (objeto da Lingüística).Como se verá na citação seguinte, a língua é apenas um "sistema de signos", "classificável entre os fatos humanos" (Saussure, 1916/1995b, p.23), e a Semiologia, como foi visto, só visa estudar"a vida dos signos no seio da vida social" (Saussure, 1916/1995b, p.24), esse "social" entendido como "um domínio bem definido no conjunto dos fatos humanos" (Saussure, 1916/1995b, p.24). O autor escreve a propósito dessa aproximação e especialmente de sua concepção de língua:

Lugar da língua nos fatos humanos.

A semiologia....

A língua, assim delimitada no conjunto dos fatos de linguagem, é classificável entre os fatos humanos, enquanto que a linguagem não o é ... .

A língua é um sistema de signos que exprimem idéias, e é comparável, por isso, à escrita, ao alfabeto dos surdos-mudos, aos ritos simbólicos, às formas de polidez, aos sinais militares, etc., etc. Ela é apenas o principal desses sistemas (Saussure, 1916/1995b, p.23) - ver passagem correspondente na edição francesa: Saussure (1916/1995a, p.32).

Finalmente, numa terceira passagem onde ele reforça a idéia da língua como sendo "o principal (dos) sistemas" (Saussure, 1916/1995b, p.24), assim como sua aproximação (como sistema de signos) com a Semiologia (como ciência dos signos), Saussure inverterá as coisas: no lugar da Semiologia como "ciência geral", da qual "a Lingüística não é senão uma parte", ele proporá a idéia da Lingüística, da qual o objeto é a língua, como sendo o "padrão (geral) de toda a Semiologia, se bem (que) a língua não seja senão um sistema particular" (Saussure, 1916/1995b, p.82). Ele escreverá assim:

Pode-se, pois, dizer que os signos inteiramente arbitrários realizam melhor que os outros o ideal do procedimento semiológico; eis porque a língua, o mais (complexo) e o mais difundido sistema de expressão, é também o mais característico de todos; nesse sentido, a Lingüística pode erigir-se em padrão (geral) de toda Semiologia, se bem (que) a língua não seja senão um sistema particular (Saussure, 1916/1995b, p.82) - ver passagem correspondente na edição francesa: Saussure (1916/1995a, p.101).

Como se pode compreender uma tal inversão? Por que, precisamente, no único subitem consagrado especificamente à Semiologia, Saussure (1916/1995b, p.23) começa por evocar a língua, por aproximá-la da Semiologia, para, em seguida, no momento de definir a Semiologia, não mais colocar a ênfase na língua, posto que se tratará para ele de propor uma Semiologia como "ciência que estude a vida dos signos no seio da vida social" (Saussure, 1916/1995b, p.24), e não mais como ciência que estude a língua? Por que, ainda que aproximando a Semiologia da língua (o objeto da Lingüística), ele diferencia a primeira da Lingüística, colocando-a como ciência geral que englobaria essa última? Como compreender que, no exato momento onde ele inverte as coisas, destaca a Língua como "o mais (complexo) e o mais difundido sistema de expressão, (e) também o mais característico de todos" (Saussure, 1916/1995b, p.82), fazendo da Lingüística o "padrão (geral) de toda Semiologia" (Saussure, 1916/ 1995b, p.82), ele faz, por outro lado, a seguinte concessão: "se bem (que) a língua não seja senão um sistema 
particular" (em comparação a um sistema mais geral)? Finalmente, não se retira de Saussure a concepção de uma diferença sutil entre as línguas (como "sistemas particulares de signos"), objeto da Lingüística, e os sistemas de signos, objeto de uma Semiologia como ciência geral?

De fato, parece que uma contradição se faz clara quando, por um lado, Saussure coloca em evidência a língua como sendo "o principal (dos) sistemas","o mais (complexo) e o mais difundido sistema de expressão, (e) também o mais característico de todos", mas também, por outro lado, a reconhece como "sistema particular de signos", abandonando-a assim na definição da Semiologia em nome de uma ciência geral de signos.

Acredita-se poder extrair de Saussure um raciocínio do tipo: todas as línguas são sistemas de signos, mas a recíproca não é verdadeira. Dito de outra maneira, todos os sistemas de signos não poderiam se definir como língua, posto que, por um lado, existiria certo sistema de signos que, se situando além da língua, a englobaria e a ultrapassaria (por analogia com a idéia da Semiologia como ciência geral, da qual a Lingüística e seu objeto - a língua - não seriam senão uma parte), e que, por outro lado, encontrar-se-iam também certos sistemas de signos se situando aquém da língua, o que faz Saussure dizer (em comparação com esses últimos sistemas - é o que pareceria!) que a língua é "o mais (complexo) e o mais difundido sistema de expressão, (e) também o mais característico de todos".

No que concerne mais particularmente à primeira afirmação, pode-se dizer que tudo pareceria se passar como se a língua fosse efetivamente um "sistema de signos", mas um "sistema particular", em oposição a um sistema de signos mais geral. Nesse sentido, não se poderia admitir que quando ele falou de uma "ciência geral dos signos" - a Semiologia - Saussure não concebia também um sistema de signos igualmente geral enquanto pressuposto e objeto de uma ciência geral dos signos, mas sem o nomear explicitamente? Saussure não conceberia aqui a Semiologia como "ciência geral", da qual "a Lingüística não é senão uma parte", se não

tivesse também concebido que seu objeto seria todos

o. os sistemas de signos: o sistema geral (que se situa além das línguas e, então, do objeto da Lingüística, mas que constitui o objeto de uma ciência igualmente geral - a

414 Semiologia) e os sistemas particulares (que constituem as línguas - objeto tanto da Lingüística, quanto da Semiologia)? No caso de uma resposta afirmativa, como compreender mais especificamente este sistema geral de signos, assim como a oposição entre esse e os sistemas particulares de signos?

Para melhor precisar esta discussão relativa à distinção entre os sistemas geral e particular de signos, assim como à sutil diferença entre, por um lado, a língua como sistema particular de signos, objeto da Lingüística e parte dos interesses da Semiologia, e, por outro lado, o sistema geral de signos, outro objeto da Semiologia, será necessário analisar em seguida algumas passagens que dizem respeito às distinções que Saussure faz entre a língua e a fala na linguagem.

\section{Para caracterizar a língua, Saussure escreve:}

Mas o que é a língua? Para nós, ela não se confunde com a linguagem; é somente uma parte determinada, essencial dela, indubitavelmente. É, ao mesmo tempo, um produto social da faculdade de linguagem e um conjunto de convenções necessárias, adotadas pelo corpo social para permitir o exercício dessa faculdade nos indivíduos (Saussure, 1916/1995b, p.17) - ver passagem correspondente na edição francesa: Saussure (1916/1995a, p.25).

Mais adiante, Saussure retoma essa idéia da língua como sendo parte da linguagem, sublinhando que ela é essencialmente social, e que é necessário então compreendê-la como linguagem de um certo grupo social. Ele escreve a respeito disso:

Evitando estéreis definições de termos, distinguimos primeiramente, no seio do fenômeno total que representa a linguagem, dois fatores: a língua e a fala. A língua é para nós a linguagem menos a fala. É o conjunto dos hábitos lingüísticos que permitem a uma pessoa compreender e fazer-se compreender.

... É mister uma massa falante para que exista uma língua. Em nenhum momento, e contrariamente à aparência, a língua existe fora do fato social, visto ser um fenômeno semiológico. Sua natureza social é um de seus caracteres internos (Saussure, 1916/1995b, p.92) - ver passagem correspondente na edição francesa: Saussure (1916/1995a, p.112).

Como se pode ver, o autor distingue nesse "fenômeno total que representa a linguagem" "dois fatores: a língua e a fala". Para caracterizar mais particularmente a fala, por oposição à língua, Saussure escreverá: 
Quando ouvimos falar uma língua que desconhecemos, percebemos bem os sons, mas devido à nossa incompreensão, ficamos alheios ao fato social.

A parte psíquica não entra tampouco totalmente em jogo: o lado executivo fica de fora, pois a sua execução jamais é feita pela massa; é sempre individual e dela o individuo é sempre senhor; nós a chamaremos fala (parole) (Saussure, 1916/1995b, p.21) - ver passagem correspondente na edição francesa: Saussure (1916/1995a, p.30)

No que concerne essa oposição entre língua e fala, compreende-se aqui que se a primeira corresponde à linguagem de um determinado grupo social, a segunda é então a linguagem individual. Se se toma emprestado de Saussure sua terminologia que valoriza a expressão "sistema", se poderia, de outra maneira, caracterizar a língua e a fala como sendo, ambas, sistemas particulares de signos, mesmo que elas se diferenciem entre si quanto ao grau de particularidade: a primeira, menos particular, relativa a uma "massa falante", à dimensão humana e social dos sistemas de signos, se restringindo assim a um grupo social particular, ao "conjunto de convenções necessárias, adotadas pelo corpo social para permitir o exercício dessa faculdade (da linguagem) nos indivíduos" (Saussure, 1916/1995b, p.17), enquanto a segunda se limitaria aos sistemas individuais de signos.

Saussure oporá também a língua e a fala em função de um outro critério: a primeira seria unicamente psíquica, enquanto a segunda seria psicofísica. Evocando o exemplo da produção dos sons necessários à fala, o autor sublinha efetivamente seu componente físico e termina por resumir as oposições entre a língua e a fala, integrando-as, uma e outra, nesse fenômeno total que é a linguagem:

O estudo da linguagem comporta, portanto, duas partes: uma, essencial, tem por objeto a língua, que é social em sua essência e independente do indivíduo; esse estudo é unicamente psíquico; outra, secundária, tem por objeto a parte individual da linguagem, vale dizer, a fala, inclusive a fonação e é psico-física (Saussure, 1916/1995b, p.27) - ver passagem correspondente na edição francesa: Saussure (1916/1995a, p.37)

Se por um lado o autor opõe a língua à fala, por outro lado ele admite existir um único momento em que elas se encontram. Mais precisamente, para explicar as mudanças que a língua sofre, ele colocará em primeiro plano o papel das alterações da fala. Ainda que atribuindo uma importância secundária à fala relativamente à existência da língua, ele diz que todas as suas modificações vão depender das inovações introduzidas por aquela. Saussure escreve:

A essa separação da fonação e da língua se oporão, talvez, as transformações fonéticas, as alterações de sons que se produzem na fala, e que exercem influência tão profunda nos destinos da própria língua. Teremos, de fato, o direito de pretender que esta exista independentemente de tais fenômenos? Sim, pois eles não atingem mais que a substância material das palavras. Se atacam a língua enquanto sistema de signos, fazem-no apenas indiretamente, pela mudança de interpretação que daí resulta ... .

E o que dizemos da fonação será verdadeiro no tocante a todas as outras partes da fala (Saussure, 1916/1995b, p.26) - ver passagem correspondente na edição francesa: Saussure (1916/1995a, p.36).

E mais adiante, Saussure retoma a mesma idéia: "Nada entra na língua sem ter sido antes experimentado na fala, e todos os fenômenos evolutivos têm sua raiz na esfera do indivíduo" (Saussure, 1916/1995b, p.196) - ver passagem correspondente na edição francesa: Saussure (1916/1995a, p. 231).

Ao falar sobre a linguagem, Saussure é ainda menos claro. Fica evidente, pelo que se viu nas citações precedentes, que ele a concebe como um "fenômeno total", no qual se distinguem "dois fatores: a língua e a fala" (Saussure, 1916/1995b, p.92). Mas ele não precisa aqui tratar dos únicos fatores que se pode encontrar na linguagem; e também nada especifica em outra passagem onde ele escreve: "a linguagem tem um lado individual (a fala) e um lado social (a língua), sendo impossível conceber um sem o outro" (Saussure, 1916/1995b, p.16). Em resumo, por um lado, o autor parece dizer que a linguagem seria composta apenas pela língua e pela fala, mas, por outro lado tem-se a impressão, ao lê-lo, que a linguagem se situaria mais além do simples conjunto constituído pela língua mais a fala, especialmente quando ele escreve:

Tomada em seu todo, a linguagem é multiforme e heteróclita; a (cavalo sobre vários) domínios, ao mesmo tempo física, fisiológica e psíquica, ela pertence além disso ao domínio individual e ao domínio social ...

... poder-se-ia objetar que o exercício da linguagem repousa numa faculdade que nos é dada pela Natu- 
reza, ao passo que a língua constitui algo adquirido e convencional, que deveria subordinar-se ao instinto natural em vez de adiantar-se a ele.

Eis o que pode se responder (Saussure, 1916/1995b, p.17) - ver passagem correspondente na edição francesa: Saussure (1916/1995a, p. 25).

Como compreender essa última: "Eis o que pode se responder"? Saussure estaria buscando aqui justificar um eventual sentimento de limitação, uma eventual impossibilidade que ele tivesse experimentado para dizer alguma coisa a mais sobre a supremacia da linguagem sobre a língua. Teria ele preferido se exprimir mais sobre essa supremacia, assim como sobre a linguagem, sobre seus elementos constitutivos, sobre sua relação com a Semiologia?

Se, por um lado, a linguagem fosse um simples conjunto constituído pela língua mais a fala, ela seria também como as duas um sistema particular de signos, o que entraria em contradição com seu lado"multiforme e heteróclita; a (cavalo sobre vários) domínios". Por outro lado, a Semiologia, como ciência geral constituindo uma parte da Psicologia Social, seria então o estudo da língua, o que significa dizer sinônimo da Lingüística, o que introduziria uma outra contradição, pois a Semiologia é aqui concebida como incluindo a Lingüística, e se situando, assim, mais além dela.

Pode-se questionar se não se deve ver na noção de linguagem, implicitamente sugerida, a concepção de um sistema geral de signos como objeto e pressuposto dessa "ciência geral dos signos" - a Semiologia. 0 autor dá efetivamente a impressão de hesitar entre a valorização da língua por sua dimensão humana, social e psíquica, e sua desvalorização, considerando o fato de ela constituir apenas um sistema particular de signos. Ele parece estar em busca de alguma coisa que detivesse essa dimensão humana, social e psíquica da língua, mas ao mesmo tempo permitindo o acesso a um sistema geral de signos. Estaria ele procurando uma espécie de linguagem geral reveladora de uma mesma natureza humana, independentemente das diferenças temporais, geográficas, culturais, sociais, etc.?

im Sejam quais forem as respostas a esses questiona罝 mentos, o que se tem certo, como visto acima, é que a o. linguagem se situa em Saussure do lado da "natureza" (que é universal e se opõe à cultura, ao social, que são relativos, particulares), mas também do lado "social", do "físico", do "individual", o que introduz uma noção de natureza humana lingüística, de psiquismo lingüístico, ao mesmo tempo social e universal. Isso nos leva a supor que, em Saussure, exista uma noção de linguagem universal e atemporal que expressa o psiquismo do homem em geral; e também uma noção de linguagem como comportando um sistema geral e sistemas particulares de signos (por oposição à língua, constituída unicamente por um sistema particular de signos, que é o objeto da Lingüística), respectivamente atemporal e temporais, como objeto da Semiologia, essa "ciência geral" que "estuda a vida dos signos no seio da vida social", formando assim "uma parte da Psicologia Social e, por conseguinte, da Psicologia Geral", da qual "a Lingüística não é senão uma parte". Em resumo, a hipótese aqui é precisamente que se encontra, em Saussure, implicitamente sugerida, a noção de linguagem como sendo constituída pela língua mais a fala, essas sistemas particulares de signos, e também por um sistema universal de signos.

Como essa noção não está diretamente enunciada por Saussure, decidiu-se verificar se a hipótese acima em destaque era ou não compartilhada por outros autores, consultando os comentadores da obra de Saussure. Assim, no Nouveau Dictionnaire Encyclopédique des Sciences du Langage, mais precisamente no subitem consagrado às "unidades lingüísticas mínimas" (os signos), os autores começam por evocar o arbitrário do signo em Saussure, caracterizando-o como sendo relativo, social, variando de uma língua para outra. Eles lembram em seguida a existência de signos universais que chamam "universais substanciais" (universais lingüísticos), procurando esclarecer que eles apenas aparentemente se opõem à noção saussuriana de arbitrário do signo. E eles terminarão integrando as duas noções, sublinhando que é possível admitir a coexistência dos signos arbitrários e dos signos universais:

A maneira mais radical de afirmar o arbitrário lingüístico consiste em sustentar que as unidades mínimas usadas por uma língua particular não são fundadas em nada mais que seu uso lingüístico, e não possuem então existência fora dessa língua, ou, em todo caso, da linguagem em geral ... .

Podemos contestar o argumento da diversidade dizendo que as variações alegadas se devem a uma análise lingüística superficial: uma análise aprofundada faria aparecer universais (lingüísticos), e todas as línguas escolheriam os elementos de base de suas combinações dentro do mesmo repertório de 
elementos semânticos ou fonéticos. Assim, para a maior parte dos generativistas, os componentes fonológico e semântico (105), que operam no termo da descrição lingüística, devem representar os enunciados numa metalinguagem universal da qual os símbolos designariam então os universais substanciais suscetíveis de serem reencontrados nas mais diversas línguas... .

Essa crítica, que diz respeito ao argumento estruturalista habitual em favor do arbitrário do corte lingüístico, não atinge no entanto a tese em si, por que os universais alegados podem, e, no contexto da teoria generativa, devem ser atribuídos a uma faculdade da linguagem, distinta das outras faculdades humanas. Nada impede então que se admita um arbitrário, que não seria mais aquele desta ou daquela língua em particular, mas da linguagem em geral. É a lingüística cognitiva (276s.), aqui também, que contradiz fundamentalmente o estruturalismo. Para ela, não apenas existem universais lingüísticos, mas estes também estão determinados por caracteres gerais do pensamento, observáveis fora da expressão e da comunicação lingüísticas (Ducrot \& Schaeffer, 1995, p.276) - tradução desta passagem proposta pelo autor desta pesquisa.

Como se pode ver, o dicionário precisa, por um lado, que existam "os universais substanciais (os signos universais) suscetíveis de serem reencontrados nas mais diversas línguas". Eles podem coexistir ao lado dos signos arbitrários, particulares, de um certo sistema lingüístico. Dito de outra forma, o enfoque estruturalista de Saussure não seria incompatível com a hipótese relativa à existência desses universais. Mas, por outro lado, o mesmo dicionário não traz nenhuma confirmação específica a respeito da hipótese acima levantada, a saber, de que haveria em Saussure tanto a concepção de um sistema universal geral de signos, quanto a noção da linguagem como sendo constituída por esse mesmo sistema, e também pela língua e pela fala, essas sendo vistas como sistemas particulares de signos. Ao contrário, os signos universais são aqui valorizados para caracterizar o enfoque da lingüística cognitiva.

Pretende-se a seguir aprofundar essa mesma hipótese, considerando dessa vez algumas outras pistas que Saussure dá quando aborda a questão dos objetos da Lingüística e da Semiologia.

Em relação ao objeto da Lingüística, pode-se agora retomar a idéia segundo a qual ele seria primeiramente a língua. Pode-se também admitir como sendo também a fala, mas apenas quando essa influencia de fato a língua. Como já foi visto, Saussure parece crer que toda transformação da língua depende das alterações, das inovações da fala. Em relação a esse objeto da Lingüística, Saussure escreve:

Lingüística da língua e lingüística da fala

Com outorgar à ciência da língua seu verdadeiro lugar no conjunto do estudo da linguagem, situamos ao mesmo tempo toda a Lingüística ... .

A atividade de quem fala deve ser estudada num conjunto de disciplinas que somente por sua relação com a língua têm lugar na Lingüística (Saussure, 1916/1995b, p.26) - ver passagem correspondente na edição francesa: Saussure (1916/1995a, p.36).

Sobre este mesmo assunto, Saussure acrescenta:

Mas todas as inovações da fala não têm o mesmo êxito e, enquanto permanecem individuais, não há por que levá-las em conta, pois o que estudamos éa língua; elas só entram em nosso campo de observação no momento que a coletividade as acolhe (Saussure, 1916/1995b, p.115) - ver passagem correspondente na edição francesa: Saussure (1916/1995a, p.138).

Aparece aqui que o objeto por excelência da Lingüística é a língua, mas que eventualmente poderia se tornar a fala, pois, afinal de contas, Saussure admite uma "lingüística da fala", desde o momento em que a coletividade acolheu suas inovações. A Lingüística se limitaria assim a dois sistemas particulares de signos: a língua e a fala, essa última sendo considerada unicamente nessas circunstâncias particulares.

No que concerne ao objeto da Semiologia, Saussure escreve:

Uma observação de passagem: quando a Semiologia estiver organizada, deverá averiguar se os modos de expressão que se baseiam em signos inteiramente naturais - como a pantomima - Ihe pertencem de direito. Supondo que a Semiologia os acolha, seu principal objetivo não deixará de ser o conjunto de sistemas baseados (no arbitrário) do signo ....

(O) significante ... O símbolo tem como característica não ser jamais completamente arbitrário; ele não está vazio, existe um rudimento de vínculo natural entre o significante e o significado ... .

A palavra arbitrário ... não deve dar a idéia de que o (significante) dependa da livre escolha do (sujeito falante) (ver-se-á, mais adiante, que não está ao alcance do indivíduo trocar coisa alguma num signo, uma vez esteja ele estabelecido num grupo lingüístico); 
queremos dizer que o significante é imotivado, isto é, arbitrário em relação ao significado, com o qual não tem nenhum laço (natural) na realidade (Saussure, 1916/1995b, p.82) - ver passagem correspondente na edição francesa: Saussure (1916/1995a, p.100).

Principalmente nessa passagem, parece que Saussure abre a perspectiva de compreender a linguagem como sendo constituída pela língua, pela fala, e por um sistema universal de signos, assim como o objeto da Semiologia como constituído ao mesmo tempo pela língua e por esse sistema universal.

Mais precisamente quando o autor evoca os "signos inteiramente naturais", o fato do significante, do "símbolo ... não ser jamais completamente arbitrário", já que "existe um rudimento de vínculo natural entre o significante e o significado", não estaria ele admitindo a existência de um sistema universal de signos?

Além disso, Saussure oporá aqui o "arbitrário do signo" ao aleatório do signo, a um "(significante que) dependa da livre escolha do (sujeito falante)", da fala, religando assim esse "arbitrário" à língua, ao "signo, uma vez esteja ele estabelecido num grupo lingüístico".

No que concerne ao objeto da Semiologia, quando Saussure sublinha aqui que esse objeto poderá ser, no futuro, tanto os "signos inteiramente naturais" quanto o"conjunto de sistemas baseados (no arbitrário) do signo", não estaria ele admitindo, ao mesmo tempo, a possibilidade de uma Semiologia "organizada" em torno de um duplo objeto: simultaneamente, do sistema universal de signos; e da língua (o objeto da Lingüística)? No caso de uma resposta afirmativa, haveria aqui uma explicação daquilo que Saussure falava da Semiologia como "ciência geral", da qual "a Lingüística não é senão uma parte". A Semiologia, englobando assim a Lingüística (e seu objeto, a língua), se ligaria também, como essa, à fala, mas apenas dentro das estritas condições sublinhadas acima, isto é, apenas quando a alteração da fala implicasse uma modificação na língua. Parece que é nesse sentido que se poderia conceber o objeto da Semiologia como sendo, ao final de contas, todos os sistemas de signos.

Seja como for, o fato de o objeto da Semiologia apresentar-se aqui no quadro de "uma observação de passagem" que Saussure faz ao tratar de uma Semiologia em gestação, não ainda "organizada", justifica, por outro lado, as tentativas realizadas acima de lançar certas hipóteses a partir das pistas indiretas deixadas pelo autor. Caberia, então, fazer agora um breve desvio de Saussure para examinar autores da literatura atual que se apoiando em Saussure fornecem fundamentos mais diretos e mais bem elaborados às hipóteses levantadas acima neste subitem. Sendo assim, no subitem seguinte serão examinadas as contribuições de Lévi-Strauss (1958/1974, 2003) para debater tais hipóteses.

\section{Lévi-Strauss: sua Antropologia Estrutural e sua abordagem dos mitos como linguagem do domínio da língua, da fala e de um sistema universal de signos}

Os mitos dão a ilustração de uma linguagem ao mesmo tempo particular e universal-geral, temporal e atemporal. A esse propósito, parece que Lévi-Strauss tem muito a ensinar. $\mathrm{O}$ autor começa se interrogando sobre a existência de uma contradição nos mitos, na medida em que eles se revelam, por um lado, aparentemente "arbitrários" (no sentido do signo saussuriano, ao qual o significante e o significado estão ligados de forma convencional, não natural, remetendo assim a um sentido cultural, particular), mas, por outro lado, semelhantes nas diversas regiões do mundo, o que indicaria seu caráter universal. A esse propósito, Lévi-Strauss escreve:

Reconheçamos, antes, que o estudo dos mitos nos conduz a constatações contraditórias. ...esses mitos, aparentemente arbitrários, se reproduzem com os mesmos caracteres, e (freqüentemente) os mesmos detalhes, nas diversas regiões do mundo. Donde o problema: se o conteúdo do mito é inteiramente contingente, como compreender que, de um canto a outro da terra, os mitos se pareçam tanto? (Lévi-Strauss, 2003, p.239) - ver passagem correspondente na edição francesa: Lévi-Strauss (1958/1974, p.237).

Lévi-Strauss segue criticando Saussure por ter ele negligenciado aquilo que se pode compreender como sendo o componente universal do signo, por ter Saussure restringido o signo ao seu lado "arbitrário" apenas. Vê-se que, nessa crítica, Lévi-Strauss visava demonstrar que os mitos são o testemunho do caráter ao mesmo tempo particular ("arbitrário") e universal do signo. Ele escreve a esse propósito:

O princípio saussureano do caráter arbitrário dos signos lingüísticos deve ser certamente revisto e corrigido ... . 
Em nada ajuda (aproximar) o mito e a linguagem: o mito faz parte integrante da língua; é pela (fala) que ele se nos dá a conhecer, ele provém do discurso.

Se queremos perceber os caracteres específicos do pensamento mítico, devemos pois demonstrar que o mito está, simultaneamente, na linguagem e (mais) além dela (Lévi-Strauss, 2003, p.240) - ver passagem correspondente na edição francesa: Lévi-Strauss (1958/1974, p.238).

Lévi-Strauss parece dizer aqui que, em Saussure, a linguagem aparece como sendo constituída apenas pelo simples conjunto da língua mais a fala, pois, segundo ele, "aproximar o mito da linguagem não resolve nada": "o mito é parte integrante da língua"e da fala, e, então, da linguagem, mas, ao mesmo tempo, se encontra também mais além dessa. Dito de outra maneira, se Lévi-Strauss situa o componente universal do mito mais além da linguagem é por que ele o compreende como estando presente, em Saussure, apenas como um sistema particular de signos, restrito, por conseqüência, ao arbitrário do signo, na língua e na fala.

Não se pode, no entanto, concordar com tal compreensão que Lévi-Strauss parece possuir da concepção de linguagem em Saussure. Efetivamente, como já foi analisado no subitem anterior, ainda que Saussure não tenha formulado direta e claramente, ele parece ter concebido a linguagem como situada mais além do simples conjunto da língua mais a fala, posto que ela seria também composta por um sistema geral-universal de signos.

Lévi-Strauss segue sua abordagem colocando em destaque esse aspecto do mito como sistema simultaneamente temporal e atemporal, idéia que vem de encontro às hipóteses deste trabalho discutidas acima no item anterior:

Acabamos de distinguir a língua e a (fala) por meio dos sistemas temporais aos quais cada uma pertence. Ora, também o mito se define por um sistema temporal que combina as propriedades dos dois outros. Um mito diz respeito, sempre, a acontecimentos passados:'antes da criação do mundo', ou 'durante os primeiros tempos', em todo caso, 'faz muito tempo.' Mas o valor intrínseco atribuído ao mito provém de que estes acontecimentos, que decorrem supostamente em um momento do tempo, formam também uma estrutura permanente. Esta se relaciona simultaneamente ao passado, ao presente e ao futuro (Lévi-Strauss, 2003, p.241) - ver passagem correspondente na edição francesa: Lévi-Strauss (1958/1974, p.239).

Depois de ter assim caracterizado o mito como "estrutura (humana) permanente", imutável no tempo, atemporal, Lévi-Strauss terminará por sublinhar seu caráter de "linguagem que trabalha num nível muito elevado", ao mesmo tempo particular e universal ("absoluto"), existindo num tempo preciso na fala e na língua - o que se pode compreender como sendo o seu aspecto particular, mas igualmente susceptível de ser traduzido em não importa qual língua - o que constitui precisamente a prova do seu caráter atemporal e universal. Ele escreverá a este propósito:

Esta dupla estrutura, ao mesmo tempo histórica e não-histórica, explica que o mito (possa) pertencer, simultaneamente, ao domínio da (fala) (e ser analisado como tal) e ao domínio da língua (na qual ele é formulado), e ainda oferecer, num terceiro nível, o mesmo caráter de objeto absoluto. Este terceiro nível possui também uma natureza lingüística, mas é, entretanto, distinto dos dois outros ... .

A poesia é uma forma de linguagem sumamente difícil de ser traduzida para uma língua estrangeira, e qualquer tradução acarreta múltiplas deformações. Ao contrário, o valor do mito como mito persiste, a despeito da pior tradução. ... O mito é linguagem; mas uma linguagem que tem lugar em um nível muito elevado, e onde o sentido chega, se é lícito dizer, a decolar do fundamento lingüístico sobre o qual começou (a circular) (Lévi-Strauss, 2003, p.241) - ver passagem correspondente na edição francesa: Lévi-Strauss (1958/1974, p.240).

Após fazer esse breve desvio para a literatura atual, mais precisamente para examinar as contribuições de Lévi-Strauss (1958/1974 e 2003) a fim de aprofundar o debate das hipóteses sobre o pensamento de Saussure levantadas no item anterior, pode-se agora retornar a Saussure para, no item seguinte, avançar esta pesquisa em busca dos elementos constitutivos da Semiologia desse autor.

\section{A Semântica em Saussure}

Pretende-se apresentar aqui um outro componente da Lingüística e, por conseqüência, da Semiologia: a Semântica, considerando sua importância para a 
análise da presente pesquisa. O objetivo deste item é discutir a Semântica em torno da qual Saussure não fez uma exposição metódica, como bem o relembra o editor crítico da edição francesa do "Curso de lingüística geral" (Saussure, 1916/1995a, p.33, 1916/1995b, p.24). O princípio fundamental da Semântica aparece em Saussure quando ele fala da aparente contradição da língua, no fenômeno, simultâneo, da imutabilidade e da mutabilidade do signo:

O signo está em condições de alterar-se porque se continua. O que domina, em toda alteração, é a persistência da matéria velha; a infidelidade ao passado é apenas relativa. Eis por que o princípio de alteração se baseia no princípio de continuidade.

A alteração no tempo assume diversas formas, cada uma das quais forneceria matéria para um importante capítulo de Lingüística. Sem entrar em pormenores, eis o que é mais importante destacar.

Em primeiro lugar, não nos equivoquemos sobre o sentido dado aqui ao termo alteração. Poder-se-ia fazer acreditar que se tratasse especialmente de transformações fonéticas sofridas pelo significante ou então transformações do sentido que afetam o conceito significado. Semelhante perspectiva seria insuficiente. Sejam quais forem os fatores de alteração, quer funcionem isoladamente ou combinados, levam sempre a um deslocamento da relação entre o significado e o significante (Saussure, 1916/1995b, p.89) - ver passagem correspondente na edição francesa: Saussure (1916/1995a, p.108).

Não se encontram aqui referências diretas ao termo "semântica", mas a seu significado como estudo das mudanças de significação. Robert (1992, p.1793) define"semântica"como"estudo da linguagem considerada do ponto de vista dos sentidos", o estudo "das relações entre o significante e o significado, das mudanças de sentido".

Vê-se também na passagem acima citada que essas mudanças seriam apenas relativas, pois, no final das contas, "o que domina, em toda alteração, é a persistência da matéria velha". Nesse sentido não se poderia compreender que Saussure se propõe a considerar a Semântica como um simples "deslocamento da relação entre o significado e o significante", e, implicitamente, a colocar a ênfase numa "Semiologia radical", no sentido de uma Semiologia que valorizasse a essência, a raiz, as origens dos signos? Não se poderia extrair desse autor a concepção de uma Semântica que faz parte da Semiologia, e que comporta uma abordagem sincrônica - no sentido de uma análise sistêmica dos elementos do signo, o significante e o significado -, assim como uma abordagem diacrônica? Mais precisamente, não se trataria aqui da concepção de uma Semântica que valoriza as transformações do signo, mais exatamente das relações entre seu significante e seu significado, ao longo de sua história, mas colocando a ênfase no seu ponto de partida, na sua origem, enfim, na imutabilidade do signo? Se sim, colocar uma tal ênfase numa Semiologia radical, assim como no aspeto imutável do signo, não remeteria ao entendimento de que em Saussure se pode encontrar essa mesma concepção de Lévi-Strauss (1958/1974, 2003) no que concerne ao mito como lugar humano (psicossocial) onde se vê um sistema de signos ao mesmo tempo particular e universal, temporal e atemporal?

Por fim, caberia examinar o último dos elementos principais constitutivos dessa Semiologia de Saussure: a Etimologia.

\section{A Etimologia em Saussure}

Pretende-se apresentar aqui um outro componente da Lingüística e, por conseqüência, da Semiologia: a Etimologia. Saussure ensina que, não sendo "nem uma disciplina distinta nem uma parte da Lingüística evolutiva", mas sim "uma aplicação especial dos princípios relativos aos fatos sincrônicos e diacrônicos", a Etimologia "remonta o passado das palavras até encontrar algo que as explique" (Saussure, 1916/1995b, p.219). A propósito dessa função essencialmente explicativa da Etimologia, o autor precisa:

A etimologia é, pois, antes de tudo, a explicação das palavras pela pesquisa de suas relações com outras palavras. Explicar quer dizer: reduzir a termos conhecidos, e em Lingüística explicar uma palavra é reduzi-la a outras palavras, (pois) não existem relações necessárias entre o som e o sentido (princípio da arbitrariedade do signo)...

A etimologia não se contenta em explicar palavras isoladas; faz a história de famílias de palavras, assim como a faz dos elementos formativos, prefixos, sufixos, etc... .

A propósito de uma palavra tomada como objeto de pesquisa, a etimologia toma emprestados seus 
elementos de (informação) tanto (da) fonética, (quanto da) morfologia, (da) semântica, etc. Para alcançar seus fins, serve-se de todos os meios que a Lingüística Ihe põe à disposição, mas não detém sua atenção na natureza das operações que está obrigada a levar a cabo" (Saussure, 1916/1995b, p.220) - ver passagem correspondente na edição francesa: Saussure (1916/1995a, p.259).

Levantados, discutidos e desenvolvidos os principais elementos constitutivos da Semiologia de Saussure, caberia a seguir passar à conclusão desta pesquisa para pensar, finalmente, se essa Semiologia poderia ser fundamento e justificativa para o método de pesquisa de revisão de literatura em psicanálise.

\section{Considerações Finais}

Depois de ter acima caracterizado brevemente a abordagem semiológica de Saussure, chegou o momento de retomar as questões principais deste estudo, para discuti-las conclusiva e resumidamente. Foram elas: No que consiste finalmente o método semiológico de Saussure? Quais seriam suas operações fundamentais? Poderia ele servir de justificativa e fundamento para o método de pesquisa de revisão de literatura em psicanálise?

Com o próprio Saussure (1916/1995b, p.24), a Semiologia é a"ciência que estuda a vida dos signos no seio da vida social"."Vida social"é definida por Saussure (1916/1995b, p.25) como o contexto dos "ritos", "costumes", etc. Com esse autor, e com o apoio de Lévi-Strauss (1958/1974, 2003), se é levado a pensar numa extensão desse contexto para os mitos, os escritos clássicos, enfim, os legados sociais de caráter universal.

"Signo lingüístico" em Saussure (1916/1995b, p.80) não é apenas uma palavra, um termo. Ele"une não uma coisa e uma palavra, mas um conceito e uma imagem acústica. Esta não é o som material, coisa puramente física, mas a impressão (empreinte) psíquica desse som, a representação que dele nos dá o testemunho de nossos sentidos". Finalmente, este autor proporá "substituir conceito e imagem acústica respectivamente por significado e significante".

Pelo que se pode entender, o procedimento semiológico começaria, num primeiríssimo tempo, por fazer a Etimologia dos signos, isto é, pela "explicação das palavras pela pesquisa de suas relações com outras palavras" (Saussure, 1916/1995b, p.220), procurando remontar seu passado até algo que as explique, mas se esforçando para não se contentar em explicá-las isoladamente e, assim, considerando a história de suas famílias, seus elementos formativos, prefixos, sufixos, etc.

Num segundo tempo começariam as operações semiológicas propriamente ditas. Valorizando-se uma abordagem radical, os signos seriam então estudados em sua aparição original no contexto dos escritos clássicos, dos mitos, enfim, dos legados sociais de caráter universal.

O terceiro tempo da Semiologia se daria com o investimento na Semântica. As transformações posteriores dos sentidos originais dos signos seriam então valorizadas. Contudo, mesmo aqui, a ênfase ainda parece estar colocada nesses sentidos primordiais, pois, como diz Saussure (1916/1995b, p.89), apesar de o"signo estar em condições de alterar-se porque se continua","o que domina, em toda alteração, é a persistência da matéria velha". Vê-se então a valorização de uma Semiologia radical no sentido do valor ser colocado na raiz, na origem do signo.

Sendo, então, o exame dos escritos clássicos aquilo que é principalmente valorizado para a prática desta pesquisa semiológica radical, não parece óbvio que aqui se encontre um fundamento e uma justificativa para o método de pesquisa de revisão de literatura?

Mas onde entra a psicanálise nisto tudo? Por que afirmar acima na introdução a hipótese de que o método semiológico justificaria e fundamentaria a revisão de literatura como método de pesquisa, especificamente em psicanálise?

Para tentar responder tal questão, alguns pressupostos hipotéticos devem ser destacados. Entende-se que, antes de mais nada, um método de pesquisa, seja ele qual for, só poderia ser considerado psicanalítico na condição de poder assegurar o acesso àquilo que é fundamental na pesquisa psicanalítica: o inconsciente. A respeito disto, Laplanche e Pontalis (1998, p.384) esclarecem: "Psicanálise... método de investigação que consiste essencialmente em evidenciar o significado inconsciente das palavras, das ações, das produções 
imaginárias (sonhos, fantasias, delírios) de um sujeito." Nesse sentido, entende-se que o método semiológico precisaria permitir o acesso a essa dimensão do inconsciente para que pudesse ser utilizado na investigação do objeto principal da pesquisa psicanalítica. Caberia então a questão: permitiria esse método semiológico acesso ao inconsciente do sujeito? Para discutir essa questão, três pontos necessitariam ser considerados. São eles:

Primeiramente, deve-se destacar que Saussure (1916/1995b, p.24) não propõe a Semiologia para servir especificamente à psicanálise, na investigação do sujeito, pois "ela constituiria uma parte da Psicologia Social". Por outro lado, tratando-se de ciência embrionária, esse autor também dirá que "(caberá) ao psicólogo determinar o lugar exato da Semiologia".

Em segundo lugar, embora não tendo diretamente postulado, Saussure parece conceber"universais da linguagem" reveladores da natureza humana profunda, conforme discutido acima especialmente no item sobre "A diferença entre Semiologia e Lingüística em Saussure". Mesmo classicamente conhecido pela "equação": linguagem é igual à língua mais a fala, pelo destaque dado ao relativo, ao arbitrário do signo, aos sistemas particulares de signos (a língua e a fala), Saussure (1916/1995b, p.82) valorizará também os signos universais, quando admite a existência simultânea de "signos inteiramente naturais", do "símbolo não ser jamais completamente arbitrário", de "um rudimento de vínculo natural entre o significante e o significado". Além disso, na abordagem da semântica, Saussure (1916/1995b, p.89) dirá que "o que domina, em toda alteração (do signo) é a persistência da matéria velha". Finalmente, tratar-se-á em Saussure de propor uma abordagem psicológica, pondo então em evidência a representação, no lugar da coisa material em si, como se viu acima a propósito de sua definição de signo (Saussure, 1916/1995b, p.80).

Em terceiro lugar, não se pode pensar que aquilo que estaria presente no homem sob a forma de universais lingüísticos naturais, na origem das transformações

in subseqüentes dos signos, recalcado, portanto, na

罡 aparência atual do signo, também não estaria presente O

$\mathbf{v} \mathbf{\nabla} \boldsymbol{\nabla}$

3 Para aprofundamento, desenvolvimento e justificativa das idéias deste parágrafo, sugere-se ao leitor interessado consultar a noção de "Semiologia Psicanalítica" em Bento (1996, item 1.2), construída a partir de Freud (1913/1974) em "Totem e Tabu", e de Lacan (1966 e 1998) em"A instância da letra no inconsciente ou a razão desde Freud", nos "Escritos". tanto no sujeito do inconsciente (fenômeno social), quanto no inconsciente do sujeito (fenômeno individual), inconsciente esse objeto por excelência da investigação psicanalítica? Se sim, não se poderia então afirmar que o método semiológico justificaria e fundamentaria a revisão de literatura como método de pesquisa, também em psicanálise? Não seria essa Semiologia radical presente no pensamento de Saussure que depuraria os ditos universais da linguagem reveladores da natureza humana lingüística inconsciente? ${ }^{3}$

Quanto à questão, também destacada acima, na introdução: "Seria o estudo de caso o método, por excelência, para a pesquisa psicanalítica, já que seria a priori nele que se poderia estudar a clínica tão valorizada pela psicanálise?", pelo menos dois pontos fundamentais poderiam ser discutidos. São eles:

Em primeiro lugar, é óbvio que a Semiologia, como revisão de literatura, não faz clínica, mas sim teoria. Contudo, parece ser um erro associar a psicanálise apenas à clínica, dissociando-a da teoria. A esse respeito, Laplanche e Pontalis (1998, p.385) esclarecem no sentido "C" do termo: "Um conjunto de teorias psicológicas e psicopatológicas em que são sistematizados os dados introduzidos pelo método psicanalítico de investigação e de tratamento". Vê-se aqui que esse sentido "C" do termo "Psicanálise" equivale, como sinônimo, ao termo "Metapsicologia", assim definido por Laplanche e Pontalis (1998, p.284): "Termo criado por Freud para designar a Psicologia por ele fundada, considerada em sua dimensão mais teórica".

Em segundo lugar, também parece estar errado considerar que o estudo de caso seja o método, por excelência, da psicanálise, porque investe na clínica. 0 tempo do "fazer a clínica" é diferente do tempo do "escrever a clínica". "Fazer a clínica" não é a mesma coisa que "escrever a clínica". Em outras palavras: "clínica" é diferente de "pesquisa clínica". O estudo de caso é um método de pesquisa; não é um método de clínica. No estudo de caso se escreve uma clínica, o que remeterá ao investimento no teórico, no metapsicológico. Sobre isto, escreve Fédida (1992, p.234): "Pensar o caso na qualidade de uma teoria enigmática processualmente 
à obra e escrevendo-se a partir de uma leitura que tem lugar entre o analista e seu paciente é sustentar que o caso resulta, de algum modo, de uma redução metodológica dos tempos narrativos dos processos em jogo, em benefício único de sua legibilidade em um texto (oral ou escrito) que dissuade qualquer relato clínico e assim 'transcende' o conteúdo do caso. Seria então sugerir que aquilo que se chama um 'caso', sem por isso tornar-se 'um caso de figura', é construído pela figurabilidade do texto teórico e assim, a partir de sua capacidade ficcional de produzir modelos clinicamente deformáveis e transformáveis. Esse texto poderia ser considerado 'metapsicológico' em razão mesmo da capacidade de possibilitar uma legibilidade sempre potencial da clínica do caso". A partir dessa citação, não se pode concluir que o estudo de caso, tanto quanto a revisão de literatura, em psicanálise, opera, precisamente, no nível metapsicológico, fazendo, então, teorização em psicanálise, e não clínica psicanalítica?

Finalmente, retoma-se agora uma última questão, sugerida acima, também na introdução: existiria de fato o risco do estudo teórico prévio, realizado no tempo da revisão de literatura, influenciar no sentido de criar pré-conceitos, levando ao encaixe da teoria no estudo de caso realizado posteriormente? A esse respeito, McDougall (1997, p.185) parece ter algo a dizer: “... há o risco sempre presente de que as nossas crenças teóricas influenciem indevidamente a nossa técnica, a ponto de que nossos analisandos possam empregar muito de seu processo analítico na tentativa de confirmar as expectativas teóricas de seus analistas!" Por essa citação, pode-se ver claramente que o investimento no teórico oferece mesmo riscos! Riscos para a clínica em si; e, obviamente, riscos também para a pesquisa dessa clínica, para sua escrita, já que essa escrita ocorreria num momento posterior, após e a partir de um momento clínico anterior.

Resta, contudo, a questão: decorreriam tais riscos de alguma suposta fragilidade do método de revisão de literatura, ou da dificuldade do analista-pesquisador de separar-se da teoria examinada num primeiro tempo, para ficar sozinho com seu "caso", seja num segundo tempo, na clínica do caso, seja num terceiro tempo, na teorização inerente à pesquisa do estudo de caso? A resposta a essa pergunta está, obviamente, sugerida nessa mesma pergunta que merece, para aprofundamento, ser objeto de outras pesquisas.

\section{Referências}

Bento, V. E. S. (1996). La passion amoureuse "toxique": une approche psychanalytique à partir de la sémiologie et du narcissisme chez Freud. Thèse de Doctorat Pas-Publié, Laboratoire de Psychopathologie Fondamentale et Psychanalyse, Université Paris 7.

Dor, J. (1985). Introduction à la lecture de Lacan. Paris: Denoël.

Dor, J. (1992). Introdução à leitura de Lacan (3a. ed). Porto Alegre: Artes Médicas.

Ducrot, O., \& Shaeffer, J. M. (1995). Nouveau dictionnaire encyclopédique des sciences du langage. Paris: Seuil.

Ducrot, O., \& Todorov, T. (1988). Dicionário enciclopédico das ciências da linguagem. São Paulo: Perspectiva.

Fédida, P. (1992). Nome, figura e memória. A linguagem na situação psicanalítica. São Paulo: Escuta.

Ferreira, A. B. H. (1975). Novo dicionário da língua portuguesa. Rio de Janeiro: Nova Fronteira.

Freud, S. (1974). Totem e tabu. In S. Freud. Edição standard brasileira das obras psicológicas completas desigmund Freud (Vol. 13, pp.11-191). Rio de Janeiro: Imago. (Originalmente publicado em 1913).

Lacan, J. (1966). L'instance de la lettre dans l'inconscient ou la raison depuis Freud. In J. Lacan. Écrits (pp.493-528). Paris: Seuil.

Lacan, J. (1998). A instância da letra no inconsciente ou a razão desde Freud. In J. Lacan. Escritos (pp.496-533). Rio de Janeiro: Jorge Zahar.

Lalande, A. (1996). Vocabulário técnico e crítico da filosofia. São Paulo: Martins Fontes.

Laplanche, J., \& Pontalis, J.-B. (1998). Vocabulário da psicanálise (2a. ed). São Paulo: Martins Fontes.

Lévi-Strauss, C. (1974). Anthropologie structurale. Paris: Plon. (Originalement publié en 1958).

Lévi-Strauss, C. (2003). Antropologia estrutural (6a. ed). Rio de Janeiro: Tempo Brasileiro.

McDougall, J. (1997). As múltiplas faces de Eros. Uma exploração psicoanalítica da sexualidade humana. São Paulo: Martins Fontes.

Robert, P. (1992). Le Petit Robert. Dictionnaire alphabétique et analogique de la langue française. Paris: Le Robert.

Saussure, F. (1995a). Cours de linguistique générale. Edition critique par Tullio de Mauro. Paris: Payot \& Rivages. (Originalement publié en 1916).

Saussure, F. (1995b). Curso de lingüística geral. São Paulo: Cultrix. (Originalmente publicado em 1916).

Recebido em: 29/3/2006

Versão final reapresentada em: 22/6/2006

Aprovado em: 3/7/2006 
